\title{
PRECIPITAÇÕES INTENSAS: UM ESTUDO ACERCA DA GÊNESE, FREQÜÊNCIA E CONSEQÜÊNCIAS DE ALGUNS EVENTOS NA REGIÃO SUL DO BRASIL
}

\section{Adriano de Souza Antunes ${ }^{1}$}

\section{Liliana de Oliveira Pereira ${ }^{2}$}

\section{Resumo}

A precipitação pluvial (chuva líquida e ou sob a forma sólida, granizo) é um dos atributos mais importantes para os estudos de climatologia, isso se deve às conseqüências que este fenômeno pode ocasionar quando ocorrido de forma excessiva, causando inúmeros danos em diversas escalas e episódios relacionados a impactos ambientais em áreas urbanas e rurais. (PEREIRA; GALVANI, 2008)Diante desta problemática, no presente trabalho, são analisados dados diários de precipitação das 461 estações pluviométricas mantidas pela Agência Nacional de Águas (ANA) distribuídas na região Sul do Brasil. O objetivo é verificar a freqüência dos eventos de precipitação intensa de acordo com a metodologia adotada, buscando os principais elementos meteorológicos que atuam na gênese e freqüência das chuvas e possível associação com os discursos vinculados às Mudanças Climáticas voltados à questão do Aquecimento Global de origem antrópica.

1 Geógrafo, Departamento de Geografia-FFLCH/USP. E-mail: adrianoantunes@usp.br

2 Geógrafa e aluna de Mestrado em Geografia Física, Departamento de Geografia-

FFLCH/USP. E-mail: liliana.pereira@usp.br 
Palavras-chave: Climatologia. Precipitação Intensa. Região Sul. Mudanças Climáticas.

\title{
1. INTRODUÇÃO
}

Entre vários fenômenos climáticos que causam transtornos à população no Brasil, enchentes, inundações e deslizamentos associados a chuvas intensas são os elementos mais costumeiramente identificados em nosso cotidiano.

\begin{abstract}
"Entretanto, as chuvas intensas podem trazer inúmeros transtornos à sociedade mesmo sem a ocorrência de inundações. Sabendo que diversos outros fenômenos ocorrem em conjunto com a chuva, tais como fortes ventos, ocorrência de granizo entre outros, os prejuízos causados por um evento de chuva intensa podem ser enormes. Milhares de pessoas perdem plantações inteiras, suas casas e bens por causa de vendavais e granizo que geralmente acompanham estes eventos". (TEIXEIRA \& SATYAMURTY, 2005)
\end{abstract}

Conhecida como a "porta de entrada das frentes frias" devido à sua localização geográfica e à movimentação das massas que provem do extremo sul do continente, a Região Sul do Brasil possui dimensões respeitáveis: “... uma área total de quase 578 mil quilômetros quadrados, dividida por três Estados - Paraná (199.554 Km²), Santa Catarina (95.985 Km²) e Rio Grande do Sul (282.184 Km²)." (AB' SABER, 2003)

Devido às "calhas naturais" existentes no relevo, as massas de ar frio, que ganham força no inverno, podem fluir em direção às outras regiões e assim caracterizar o clima no território brasileiro. Além do relevo e da posição 
geográfica, os sistemas de circulação atmosférica influenciam de forma considerável na caracterização climática da região Sul, que se distingue das demais regiões brasileiras pela homogeneidade quanto às chuvas, que permanecem praticamente constantes em quase todos os meses do ano, com ligeira intensificação no verão. (MENDONÇA \& DANNI-OLIVEIRA, 2007)

A precipitação na região sul está relacionada à atuação de vários sistemas meteorológicos, sendo principalmente os frontais (SF) e os Complexos Convectivos de Mesoescala (CCM). Em escala global, observamse influências dos Oceanos Pacífico e Atlântico, que podem causar impactos econômicos e sociais significativos na região. (SILVA, 2007)

Ao longo de décadas, esta região protagonizou inúmeros e sucessivos eventos climáticos intensos, porém nos últimos anos, a discussão a partir desses fenômenos se tornou maior à medida em que a falácia sobre as causas e os efeitos do aquecimento global se tornaram constantes.

Em 2 de outubro de 1911, quando em apenas um dia, as águas do rio Itajaí- Açú, em Blumenau, Santa Catarina, alcançaram a marca de 16,27 metros e em julho de 1983, quando, segundo Rebello (2007), o fenômeno El Niño causou diversos transtornos climáticos no Brasil que vitimaram 49 pessoas e desabrigaram mais de 197 mil devido ao grande volume de chuvas que castigou este estado.

Porém a maior enchente já registrada no sul do Brasil ocorreu no sudeste de Santa Catarina em março de 1974, quando o nível do rio Tubarão subiu mais de 10 metros e inundou o município de mesmo nome. Na época, 199 pessoas perderam a vida e 65 mil ficaram desabrigadas (Atlas de Desastres Naturais do Estado de Santa Catarina).

Recentemente, ainda em Santa Catarina, ocorreram 135 mortes devido a uma das maiores enchentes já ocorridas no estado. A população foi vitimada 
basicamente pela ocupação desordenada dos solos que ficaram facilmente encharcados devido aos $500 \mathrm{~mm}$ de chuvas registradas durante os quatro dias em que o fenômeno esteve atuando. Ou seja, um número de extrema relevância já que a média anual nesta região é de $2000 \mathrm{~mm}$. (CPTEC- Centro de Previsão do Tempo e Estudos Climáticos).

Tendo em vista todo o exposto acima descrito, neste artigo o principal objetivo é verificar a freqüência dos eventos de precipitação intensa no sul do Brasil, evidenciando os elementos que atuam na origem e variabilidade dessas chuvas, incluindo uma breve reflexão acerca da vinculação destes fenômenos com o discurso das Mudanças Climáticas Globais.

\section{DADOS E METODOLOGIA}

Para a realização do estudo, foram analisados dados diários de chuva dos últimos trinta anos (1978-2008), fornecidos pela Agência Nacional de Águas, sendo obtidos através dos 470 pluviômetros mantidos nas estações meteorológicas responsáveis pelo monitoramento pluvial no sul do Brasil, conforme a Figura 1.

Para a realização das análises, foram selecionados os dados dos últimos 30 anos, posto que no início deste período a emissão antrópica de $\mathrm{CO}_{2}$ não era tão significativa como verificado nos dias atuais e por este intervalo possuir inúmeros registros de chuvas intensas na região em questão. Desta 
maneira, sugere-se nesta pesquisa uma hipótese para correlacionar estes fatos.

No pressente artigo, define-se também eventos intensos de chuva, utilizando o conceito desenvolvido por ESPÍRITO SANTO e SATYAMURTY (2002), onde um evento é considerado intenso quando em um período de 24 horas, atinge-se um limiar de 100 a 150mm. Este critério foi utlizado, já que este volume de chuva é suficiente para causar grandes transtornos à população tanto em áreas urbanas, com inundações e caos nos sistemas de transporte, como em áreas rurais com escorregamentos de morros e perda na produção de determinados produtos agrícolas.

\section{RESULTADOS E DISCUSSÃO}

Durante o período estudado, foi verificado que a precipitação intensa não apresentou a variabilidade que é peculiar aos eventos climáticos, conforme mostra a Figura 1, pois sabe-se que o clima nunca foi e jamais será estático, sendo controlados por fenômenos considerados comuns e exaustivamente já estudados, como os Sistemas Sinópticos (Sistemas Frontais, os CCMs e as interações oceano - atmosfera). 


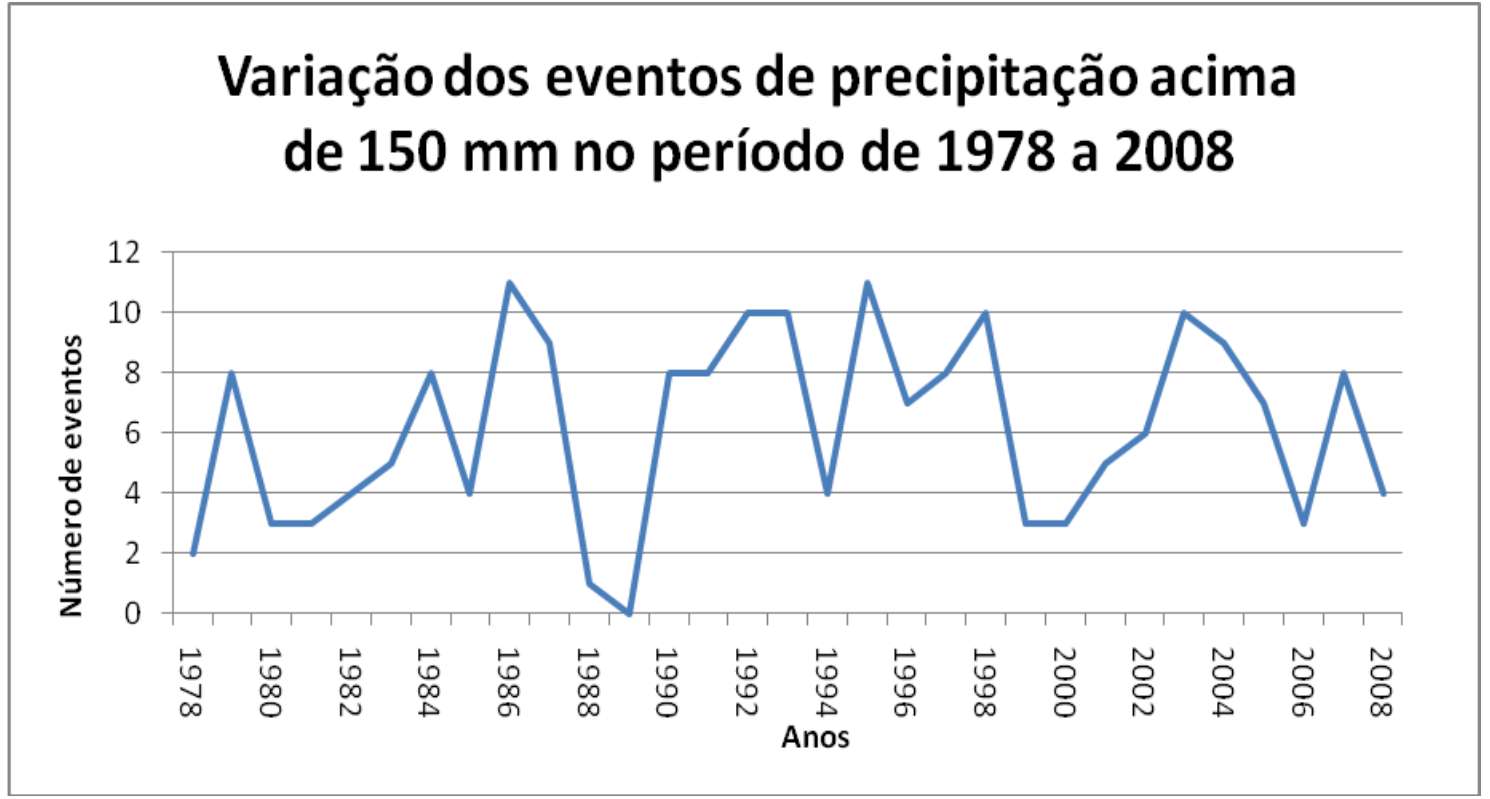

Figura 1 - Variação dos eventos de precipitação acima de 150 mm.

Através dos dados obtidos, é possível ratificar as afirmações de Ropelewski e Halpert (1987 e 1989) encontradas em diversos trabalhos: a precipitação na região sul do Brasil possui uma boa relação com a Oscilação Sul, tanto na fase positiva com o El Niño como na fase negativa com o La Niña. Essa influência da temperatura do Oceano Pacífico fica clara quando cruza-se dados de quantificação de eventos de chuva intensa e o fenômeno ENOS- El Niño Oscilação Sul, Figura 2.

O fenômeno El Niño, que representa a fase positiva do ENOS, caracteriza-se pelo enfraquecimento dos ventos alísios e o aumento da Temperatura da Superfície do Mar (TSM) no Oceano Pacífico Equatorial Leste, resultando em águas mais quentes próximas à costa oeste da América do Sul (VOITURIEZ e JACQUES, 2000).

O fenômeno oposto, La Niña, que representa a fase negativa, caracteriza-se pela intensificação dos ventos alísios e pelo declínio da TSM no 
Pacífico Equatorial Leste. (Voituriez e Jacques, 2000). Geralmente, alguns impactos do La Niña são opostos aos do El Niño, como por exemplo, os períodos de estiagem na ocorrência desse fenômeno (VAREJÃO - SILVA, 2001).

No período de 1982 a 2008, a freqüência de eventos intensos geralmente acompanha a variação da temperatura do Pacífico no El Niño, evidenciando o grande papel dos oceanos na configuração do clima e a relação com os eventos de precipitação intensa.

Índice histórico de variação de temperatura da superfície do mar x Número de eventos de precipitação

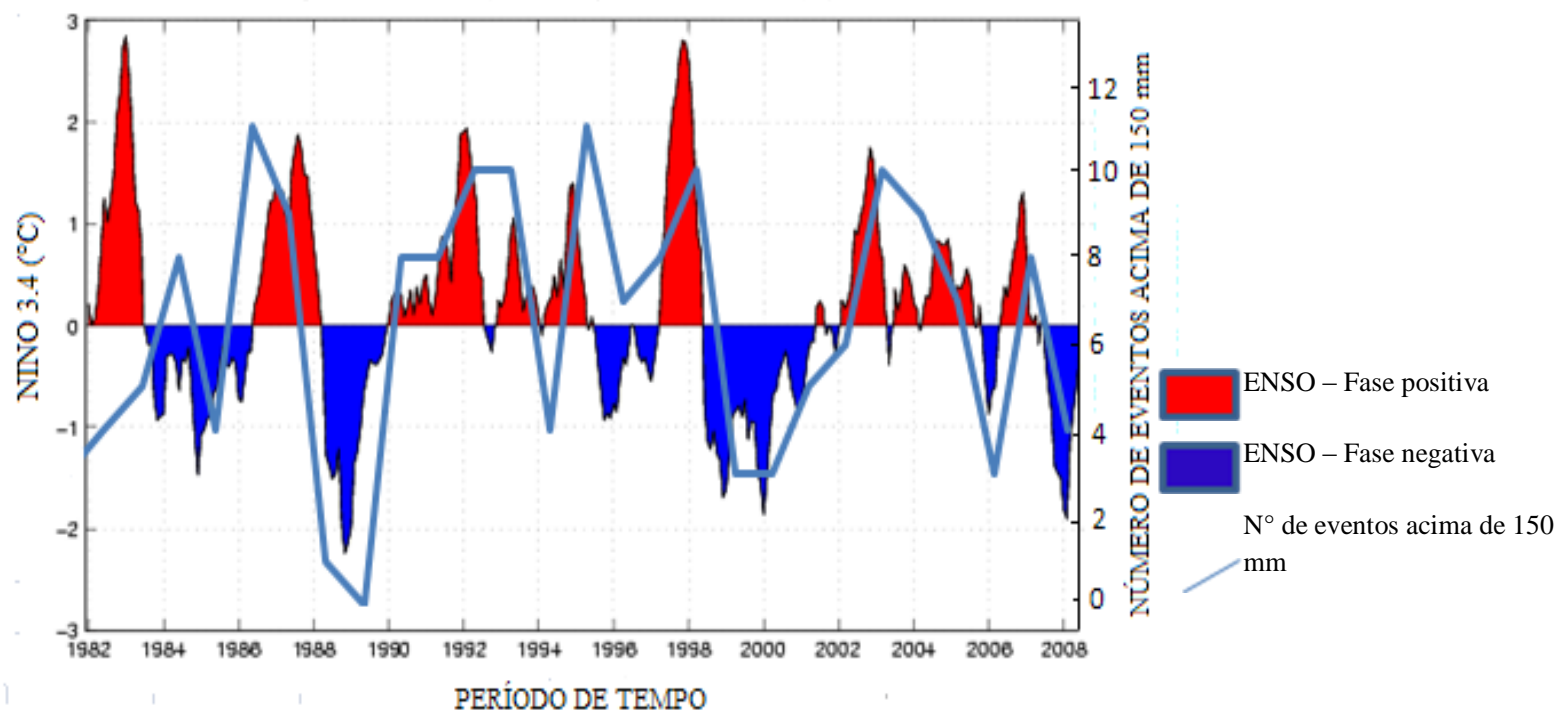

Figura 2 - Variação ENOS x precipitação intensa. Fonte: Adaptado de NOAA- National Oceanic and Atmospheric Administration

As conseqüências deste fenômeno para a região sul do Brasil são chuvas intensas de maio a julho, além do aumento da temperatura média. $O$ aumento de precipitação, nesta região em análise, está relacionado com a 
intensificação do jato subtropical associado a uma situação de bloqueio na troposfera superior, estacionando os sistemas frontais nessa região do país (VAREJÃO - SILVA, 2001).

Como exemplo cita-se as inundações catastróficas ocorridas em 1983, que afetaram praticamente todos os municípios de Santa Catarina (HERRMANN, 2001).

Portanto, é possível dizer que a variação da TSM do Pacífico age diretamente contribuindo para a gênese e freqüência dos eventos de precipitação intensa e independe da concentração de $\mathrm{CO}_{2}$ atmosférico, evidenciando que os fatores naturais determinam o clima de forma contundente e que ações antrópicas estão restritas às escalas locais.

\subsection{Freqüência}

Os eventos analisados predominaram durante o outono e o verão com 63 e 62 registros respectivamente, seguidos da primavera com 48 e o inverno com 23 registros.

Como mencionado anteriormente, o fenômeno ENOS influencia diretamente os eventos de chuva intensa, e dessa forma pode ser o grande responsável pela sazonalidade das chuvas nos anos que atuou, já que causa um aumento expressivo nos índices de precipitação principalmente entre os meses de maio a julho, de acordo com o CPTEC, ou seja, outono e início do inverno.

Nos anos em que não foi registrada a atuação do fenômeno ENOS portanto, atribui-se a distribuição dos eventos intensos aos Sistemas Frontais 
que são o dinamizador da gênese pluvial praticamente durante todo ano, podendo intensificar-se no inverno, segundo Monteiro (2001), e os CCM's que, dentre os diversos casos estudados na literatura, teve a predominância de sua atuação durante os meses de primavera e verão, como afirmam Velasco e Fritsch (1987).

\subsection{Chuva intensa na região sul e possíveis conexões com a hipótese do aquecimento global}

Nos últimos anos, especialmente na última década, grande parte dos fenômenos climáticos intensos têm sua gênese, freqüência ou intensidade atribuídas ao invólucro relacionado às Mudanças Climáticas de origem antrópica ligada às emissões de gases do efeito estufa na atmosfera.

Com os eventos de precipitação extrema na região sul do Brasil não poderia ser diferente. A mídia, com a necessidade da venda diária de seus exemplares, impressos ou eletrônicos, explora ao máximo o catastrofismo, repercurtindo em alarmismo generalizado por parte dos meios de comunicação, gerando grande alarde na sociedade em diversas escalas.

A premissa principal para o surgimento do 'catastrófico' aquecimento global seria o aumento linear da emissão do gás $\mathrm{CO}_{2}$, como mostra a Figura 3, principalmente após a revolução industrial. $\mathrm{O}$ aumento desse gás na atmosfera aprisionaria o calor em nosso planeta, causando o apocalipse climático que supostamente estaríamos vivenciando hoje, como por exemplo, grandes volumes de chuva, enchentes, tornados, e até os terremotos viraram conseqüência do aquecimento global para alguns destes atores que atuam nesta mídia sensacionalista. 
Pois bem, o que existe de certeza com relação à hipótese do aquecimento global e os eventos climáticos intensos é que não podemos realizar certas afirmações pois, contrariando tais preceitos, nada de concreto até hoje está totalmente explorado e/ ou é consenso dentro das discussões no âmbito da ciência climática.

Como evidenciado no gráfico elaborado pela NOAA (órgão norteamericano para estudos relacionados à Meteorologia, oceanos, atmosfera e clima) Figura 3, o nível de $\mathrm{CO}_{2}$ no período inicial deste estudo, 1978, era de aproximadamente 330ppm e no período final, 2008, cerca de 380ppm.

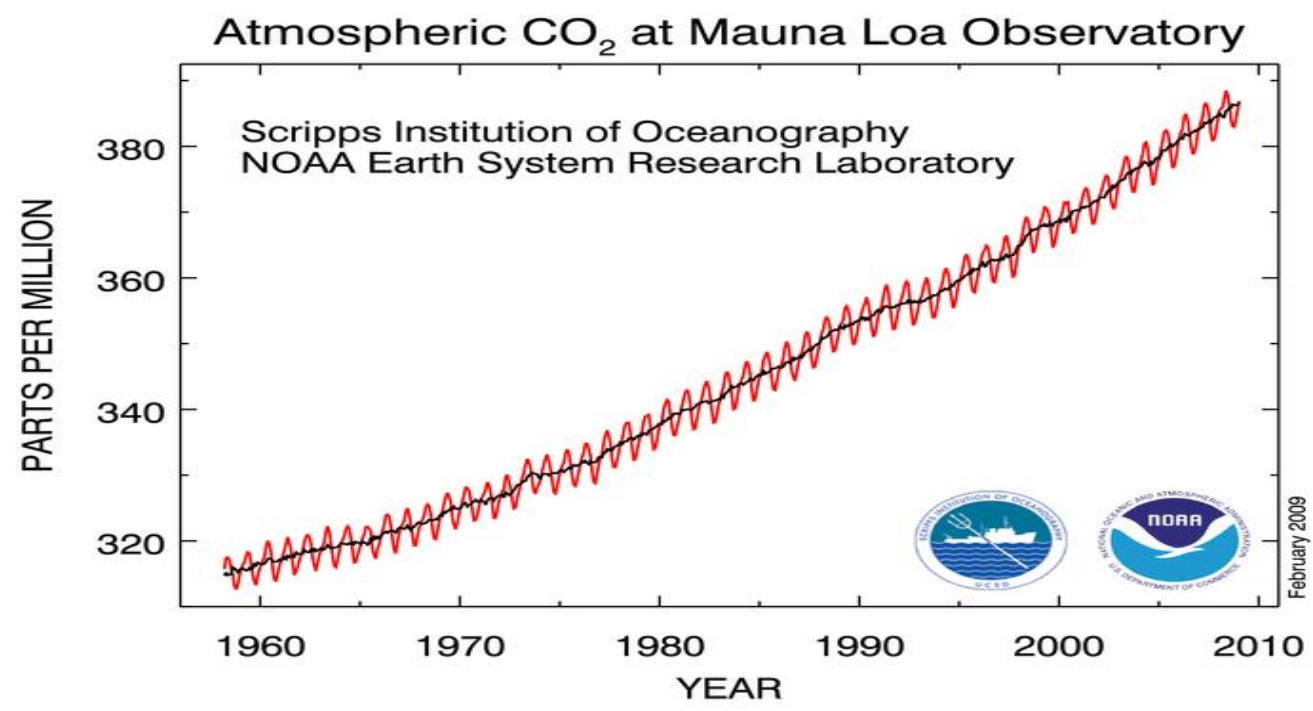

Figura $3-\mathrm{CO}_{2}$ medido em partes por milhão no observatório de Mauna Loa, localizado no Havaí no período de 1960 a 2010. Fonte:NOAA

Esse aumento espantoso dos níveis de $\mathrm{CO}_{2}$, segundo alguns pesquisadores, seria o responsável pelo aquecimento do planeta e as conseqüências desse fenômeno seriam o aumento de eventos climáticos intensos pelo mundo.

Porém de acordo com análises preliminares realizadas para a elaboração deste trabalho, especificamente na região sul do Brasil tais 
fenômenos não estão diretamente ligados. Pois, como exposto, foi verificado que as chuvas intensas permaneceram com a variabilidade que é peculiar aos eventos climáticos, conforme Figura 1, não ocorrendo portanto este aumento de eventos em virtude de maior concentração de $\mathrm{CO}_{2}$ como a mídia vem exaustivamente mencionando nos últimos anos.

Avaliar apenas os efeitos deste suposto aquecimento em escala planetária como simples causa e conseqüência é um grande erro, já que um dos maiores desafios da ciência é desvendar as nuances do clima da Terra, que não é regulado pura e simplesmente por fatores lineares e previsíveis. Prova disso, são os prognósticos diários de prospecção de tempo meteorológico que, mesmo utilizando tecnologia de ponta, não são capazes de gerar boletins precisos para o prazo que ultrapassa trinta dias, quiçá para aqueles que ultrapassam décadas.

Portanto, de acordo com a metodologia adotada, não foi possível estabelecer uma intrínseca relação entre o aumento dos eventos de chuva intensa ao longo dos últimos 30 anos na região sul do Brasil que pudessem ser atribuídos aos efeitos do aquecimento global, ou seja, não há uma aparente analogia entre o aumento dos níveis de $\mathrm{CO}_{2}$ na atmosfera e a freqüência de fenômenos de precipitação intensa na região em questão.

\section{CONSIDERAÇÕES FINAIS}

Não há nenhum fenômeno de origem natural e que ocorra em um curto intervalo de tempo, que cause tantos transtornos à população quanto as chuvas intensas. Dessa forma, estudos acerca desse tema nunca cessam e parecem seguir por caminhos distintos de acordo com o tipo de abordagem e metodologia utlizadas, culminando em um enorme leque de conclusões. 
Investigar as causas destes fenômenos tão complexos tornou-se um objetivo ímpar à medida que os efeitos de eventos climáticos extremos passaram não somente a dizimar populações, como também tornou-se razão para instituir-se ações com teor e engajamento político e econômico por uma expressiva parcela das nações mundiais. Algo que tomou proporções gigantescas com a falácia do aquecimento global.

Medidas mitigatórias, como redução de emissões dos gases de efeito estufa, com ações que podem ser consideradas absurdas, estão constantemente mais presentes em nosso cotidiano. Um bom exemplo de adoção desta prática é o da Prefeitura do município de São Paulo com a inspeção veicular obrigatória, apenas mais um meio lícito de arrecadação pública legitimada pela 'causa ambiental verde' sem aparente efeito prático. É também muito comum atualmente, depararmo-nos com as mais variadas propostas de projetos que envolvem cifras milionárias visando os propósitos pregados pela 'mídia verde', tal como pintar de branco os telhados de imóveis para conter o efeito estufa, como se tal medida fosse o suficientemente satisfatória para conter o aquecimento em escala global. (Ajude o planeta, os vendedores de tinta agradecem!). E quem pagará a conta? A população, sempre aquém das verdadeiras verdades inconvenientes que os meios de comunicação, em geral, insistentemente preconizam de maneira sensacionalista e catastrófica.

$\mathrm{Na}$ contramão dos fatos acima abordados, este trabalho de pesquisa procurou analisar elementos e hipóteses já confirmadas no meio científico para abordar eventos que agem em território brasileiro há milhares de anos. Poderse-ia utilizar aqui um falso consenso e produzir mais um trabalho imputando ao aquecimento global toda a causa dos efeitos extremos do clima, mas preferimos agir com a cautela que a ciência laica e neutra exige em toda a sua dialética e imparcialidade. 
Tragédias associadas à chuvas intensas se tornaram constantes e só aumentaram com o passar dos anos. Poderíamos concluir que as mudanças climáticas estariam de fato agindo, mas não é possível deixar de evidenciar a intensa urbanização ocorrida nas últimas décadas e a conseqüente falta de planejamento do espaço. Nos locais onde o clima se expressa de forma mais evidente como, por exemplo, a região do Vale do Itajaí em Santa Catarina, os desastres ocorrem mais freqüentemente devido principalmente à ocupação de áreas de risco. Já onde o espaço foi relativamente planejado, as conseqüências das tragédias tendem a ser mais tênues, como em Curitiba, no estado do Paraná.

Entretanto, vale lembrar que a região do vale do Itajaí não possui grandes indústrias ou centros empresariais, sendo composta, em grande parte, por pequenos municípios com base na economia agrícola, o que sustenta o fato de não ser uma localidade que atrai investimentos por parte das iniciativas pública e privada na região que sofre com as sucessivas catástrofes de origem climática.

Porém, em um país que, em sua totalidade, não conta com um planejamento urbano adequado e eficiente, os fenômenos climáticos intensos ditam o ritmo de desastres ao longo do tempo, fazendo-nos adotar medidas preventivas que podem amenizar esses efeitos, posto que ações governamentais em relação ao planejamento do espaço parece algo definitivamente muito distante de ser alcançado a curto e médio prazos.

\section{BIBLIOGRAFIA}

AB' SABER, A. N. Os domínios de natureza no Brasil: potencialidades paisagísticas. Ateliê Editorial. São Paulo, 2003. 
ANDRADE, K. M. Climatologia e comportamento dos sistemas frontais sobre a América do Sul. Dissertação de Mestrado. INPE, 2007.

AYOADE, J. O. Introdução à climatologia para os trópicos. Rio de Janeiro: Bertrand Brasil, 1998. 332 p.

BONATTI, J.P; RAO, V.B. Mois bariclinic instability in the development of North Pacific and South American intermediate - scale disturbances. Journal of the Atmospheric Sciences, v. 44, n¹8, September, 1987.

CONTI, J. B. Considerações sobre as mudanças climáticas globais. Revista do Departamento de Geografia. № 16. São Paulo, 2005

DOSWELL III, C. A.; BROOKS, H. E.; MADDOX, R. A. Flash flood forecasting: an ingredients - based methodology". Weather and Forecasting, V. 11, 1996.

GERÓLAMO, R. O. P.; Variabilidade interanual e decenal do ciclo anual da temperatura da superfície do mar no Pacífico Sul. Dissertação de Mestrado. São José dos Campos. INPE, 2008.

HERRMANN, Maria Lúcia de Paula (org.). Atlas de Desastres Naturais do Estado de Santa Catarina. Florianópolis. IOESC, 2005, 146 p.

MARENGO, J. A.; NOBRE, C. A. Lições do Catarina e do Katrina: As mudanças do Clima e os Fenômenos Extremos. Ciência Hoje v.37 , p. 22-27, 2005.

MENDONÇA, F; DANNI - OLIVEIRA, I. N. Climatologia: noções básicas e climas do Brasil". São Paulo. Oficina de textos, 2007.

PEREIRA, L. O; GALVANI, E. Eventos pluviais extremos: análise comparativa entre observações de radar e pluviômetros de superfície. (CD ROM). In: Encontro Internacional Geografia: Tradições e Perspectivas, São Paulo, 2008. Anais. São Paulo: FFLCH/ USP, 2008.

PEZZI, L. P. Previsões regionais sazonais e comparações com observações para o Sul do Brasil durante o episódio de El Niño/Oscilação Sul 97/98. (CD ROM). In: Congresso

Brasileiro de Meteorologia 10., Brasília, 1998. Anais. São José dos Campos: INPE, 1998.

PHLILANDER , S. G. El Niño, La Niña, and the Oscillation. New York: Academic Press, v. 46 International Geophisics Series, 1989. 239p. 
REBELLO, E. R. G. Anomalias climáticas e seus impactos no Brasil durante o evento "El Niño" de 1982-83 e previsão para o evento "El Niño" de 1997-98. Instituto Nacional de Meteorologia, 1997.

ROPELEWSKI, C. F.; HALPERT, M. Global and regional scale precipitation patterns associated with the El Niño/Southern Oscillation. Montlhy Weather Review, v. 115, n. 8, p.1606-1626, 1987.

SEVERO, D.L.; Estudos de casos de chuvas intensas no Estado de Santa Catarina. Dissertação de Mestrado. São José dos Campos. INPE, 1994.

SILVA, I. R.; Variabilidade sazonal e interanual das precipitações na região sul do Brasil associadas às temperaturas dos oceanos Atlântico e Pacífico. Dissertação de Mestrado. São José dos Campos. INPE, 2001.

STUDZINSKI, C. Um estudo da precipitação na região Sul do Brasil e a sua relação com os Oceanos Pacífico e Atlântico tropical Sul. 99 p. Dissertação (Mestrado em Meteorologia) - Instituto Nacional de Pesquisas Espaciais, São José dos Campos, 1995.

TEIXEIRA, M. S., Atividade de Ondas Sinópticas Relacionada com Episódios de Chuvas Intensas na Região Sul do Brasil. Dissertação de Mestrado. Instituto Nacional de Pesquisas Espaciais. São José dos Campos, 2003.

ROCKWOOD, T.A., MADDOX, R.A. Mesoescale and Synoptic leading to intense convection: The case of 7 June 1982. Weather and Forecasting, 3; 5168 ; March 1988.

VOITURIEZ, B; JACQUES, G. EI Niño: fact and fiction. Paris: IOC Ocean Forum Series/ UNESCO Publishing, 2000. 128 p. 